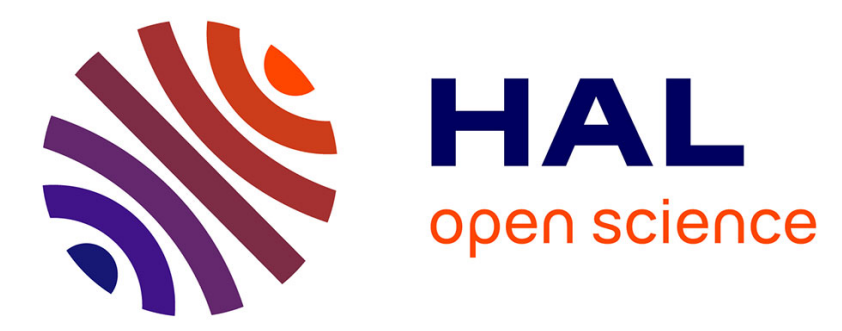

\title{
An Approach for Customer Requirements Acquisition Based on Time Iteration
}

Wen-Dan Yang, Guo-Zhong Cao, Jun-Lei Zhang, Chuan He

\section{To cite this version:}

Wen-Dan Yang, Guo-Zhong Cao, Jun-Lei Zhang, Chuan He. An Approach for Customer Requirements Acquisition Based on Time Iteration. 19th International TRIZ Future Conference (TFC), Oct 2019, Marrakesh, Morocco. pp.187-203, 10.1007/978-3-030-32497-1_16 . hal-02905533

\section{HAL Id: hal-02905533 \\ https://hal.inria.fr/hal-02905533}

Submitted on 23 Jul 2020

HAL is a multi-disciplinary open access archive for the deposit and dissemination of scientific research documents, whether they are published or not. The documents may come from teaching and research institutions in France or abroad, or from public or private research centers.
L'archive ouverte pluridisciplinaire HAL, est destinée au dépôt et à la diffusion de documents scientifiques de niveau recherche, publiés ou non, émanant des établissements d'enseignement et de recherche français ou étrangers, des laboratoires publics ou privés.

\section{(c)(1)}

Distributed under a Creative Commons Attribution| 4.0 International License 


\title{
An Approach for Customer Requirements Acquisition Based on Time Iteration
}

\author{
Wen-Dan Yang ${ }^{1,2 *[0000-0003-4646-249 X]}$, Guo-Zhong Cao ${ }^{1,2[0000-0002-2939-5566]}$, Jun-Lei \\ Zhang ${ }^{1,2[0000-0003-2280-6104]}$, Chuan $\mathrm{He}^{1,2[0000-0003-4583-6058]}$ \\ ${ }^{1}$ Hebei University of Technology, Tianjin 300401, China \\ ${ }^{2}$ National Engineering Research Center for Technological Innovation Method and Tool, Tian- \\ jin 300401, China \\ ellen0745@163.com
}

\begin{abstract}
Acquiring customer requirements (CRs) is important for enterprises to compete in marketplace since inexhaustible innovation chances could be discovered from CRs. However, it is insufficient to generate ideas for innovation solely depending on the market-pull CRs acquisition method or technologydriven CRs acquisition method. From the time dimension, these two traditional methods put different emphasis on CRs: the market-pull method focusing on digging CRs for design improvement from existing products while the technology-driven method pays more attention on CRs that future products need to satisfy sustainability in the market. This paper proposes a systematic approach for CRs acquisition on the basis that CRs at different time period have different impacts on innovation. The two traditional acquisition methods can be integrated based on time iteration. Firstly, CRs are divided into past customer requirements (PCRs), current customer requirements (CCRs) and future customer requirements (FCRs) in time dimension. Secondly, we believe that PCRs and their potential evolution information can be acquired by analysis of patents, CCRs can be identified by making use of tools in the market-pull CRs acquisition method, and FCRs can be predicted through evolutionary knowledge in TRIZ. Finally, a case study is provided to validate the feasibility of the approach.
\end{abstract}

Keywords: Customer requirements (CRs) acquisition, Time iteration, Marketpull CRs acquisition method, Technology-driven CRs acquisition method, Patent analysis, Evolutionary knowledge.

\section{Introduction}

Defining and predicting customer requirements (CRs) is crucial in order to satisfy customer needs and ensure supplier success for the present and future [1]. But neither engineers in sales department nor engineers in R\&D department have no systematic approach to comprehensively and accurately discover, identify and predict CRs throughout the whole time range, since sales department engineers always focus on capturing the voice of their current and future customers [2] and R\&D department 
engineers pay more attention on CRs that lied in existing products and future technologies [3].

The method of using customers as the research source for CRs acquisition is usually considered as the market-pull CRs acquisition method [3], and its research data include the customer satisfaction, user experience, and users' behavior in online data systems. Customer satisfaction analysis [4] can describe CRs qualitatively to sort CRs for importance as well as explain the ambiguity of them, but it cannot discover CRs since CRs are inputs of this type of analytical method. The user experience analysis [5] investigates the reliability, validity and sensitivity of standardized questionnaires, sample sizes and usability problems to improve the accuracy of market-pull CRs acquisition tools both from pre-acquisition and post-analysis. The analysis of users' behavior in online data system focuses on collecting CRs efficiently under extreme data condition [6]. Further, the importance of quick response to dynamic CRs has been considered, Chong et al [7] suggested using neural network techniques to capture new CRs in the temporal space between the product conceptualization and market introduction. Although the market-pull method takes a glimpse of the dynamics and inducible property of CRs, it can only manage CRs that currently active. What's more, past states of CRs are missed leading to a lack of objectivity and continuity of needs, and unexpected needs which would made the product a top shot in the market have not been considered as well.

The method of using products as the research source for CRs acquisition is usually considered as the technology-driven CRs acquisition method [3], and its research data concentrate on products and patents. Cao et al [8] demonstrated that CRs can be obtained through the patent technical information analysis. He also presented the innovation direction of a product in different development cycles based on laws of needs evolution after sorting CRs of several mature products [9]. Zhang et al [10] proposed a CRs acquisition process model which integrates laws of needs evolution with laws of the technology evolution in TRIZ to predict future CRs qualitatively from both macro and micro levels. However, the technology-driven method does not have continuous communication with customers in the CRs analysis model, resulting in a decrease in the accuracy of the results. Ding [3] discussed that the integration of marketpull and technology-driven model would be a main way to determine CRs. More precisely, he proposed using market-pull methods to interact with customers before the detail design whereas the proposed approach highlights roughness and did not reveal the intrinsic mechanism of the combination of those two traditional methods.

In this article, a systematic CRs acquisition method is proposed based on time iterations to acquire past customer requirements (PCRs), identify current customer requirements (CCRs) and predict future customer requirements (FCRs). Comparison of tools in the market-pull CRs acquisition method and technology-driven CRs acquisition method in time dimension is discussed in Section 2 along with the intrinsic mechanism of combining those two methods is stated. The approach for the CRs acquisition based on time iteration is illustrated in Section 3 followed by introducing seven steps of this approach. Hand installation pincers for operating the spring band hose clamps is selected as an example to implement CRs reacquisition in Section 4, followed by the conclusions in Section 5 . 


\section{Two Traditional Acquisition Methods in Time Dimension}

Kano divided CRs into basic requirements, regulate requirements, attractive requirements, indifferent requirements and reverse requirements [11]. But it cannot help to inspire as one partake in a creative action, although this classification method can differentiate CRs as it is more of an analytical tool. For different characteristics of CRs in different time dimension, we firstly make the following classification: CRs that have been realized in the past of the product, CRs that customers currently request for design, and CRs that future products need to satisfy in the market. They are briefly referred as past customer requirements (PCRs), current customer requirements (CCRs), and future customer requirements (FCRs). Therefore, tools of the market-pull method and technology-driven method are analyzed according to the performance of obtaining these three types of CRs.

Market-pull methods take customers as research subjects. Customers' current problems and feedback from the products on hand are the main research data [12]. Therefore, this type of methods can capture CCRs well. Moreover, as the potential (unexpressed) needs of customers are continuously tapped, the ambiguity of CCRs will continue to weaken, and research results will become more comprehensive and accurate. However, CRs that have been well achieved and performed in past and existing products are often easily be overlooked by customers during communication, which means the depth and width of PCRs are inferior to those of the CCRs. Although, the scope of research data sources of PCRs can expand to some extent with the help of users' online behavior analysis, PCRs obtained from the market-pull method remains limited. For FCRs which can help facilitate innovation, the market-pull method is short of inducible research data, and can only rely on the expert system to provide guidance, so it is difficult to carry out more in-depth investigation.

Technology-driven methods take products as research subjects. Function is the nature of survival of a product, thus CRs can be acquired through the function analysis of existing products [3]. More precisely, the hierarchical function model and TRIZ substance-field model, two of the most common used tools for the function analysis, can help sort out relationships between PCRs and identify FCRs caused by nonstandard functions. Petrov [9] suggested that CRs can be implemented through known and new functions, presented five laws of needs evolution to predict FCRs. Patent library collects all solutions of every development cycle of a product, therefore analysis of patents ratio analysis of products can obtain a wider range of PCRs [8]. In particular, the development of the patent map technology can not only effectively deal with the information displayed by documents of one patent, but also take groups of patents as a system to explore its potential information. LESE (Laws of Engineering System Evolution) developed by analysis of patents is one of the contributions that engineers have proved useful to generate a requirements list [13]. However, technology-driven method suffer a poor performance in acquiring CCRs compared to marketpull method. First, the documents of a patent is publicized until 18 months from its filing date. Therefore, new patents, also can be identified as new CRs, generated during this temporal space cannot be included in their analysis model. Secondly, the con- 
tinuous communications with customers are missing in technology-driven method, its understanding of CCRs lacks credibility.

In summary, the suggested tools in market-pull methods and technology-driven methods are scored according to the performance in acquiring PCRs, identifying CCRs and predicting FCRs (they are called functions in this paragraph). We used a five-tiered scale to define a measurement logic. The value does not have a specific meaning, what is important is the gap between the values. Firstly, identify the tools that perform best for each function, giving a maximum of 5 points. For example, the 'analysis of patent technical information and patent mapping technology' scored 5 points for acquiring PCRs, the 'laws of engineering system evolution' scored 5 points for identifying CCRs and the 'mining potential needs of customers' scored 5 points for predicting FCRs. Secondly, compared the other 7 tools with the best performing tool for each function, a five-level division of performance for the same function is obtained. At last, compared the degree to which the three functions are implemented by the same tool to revise the scores. For visualization, the scores are plotted in a radar chart. Axes on the right correspond to four tools in market-pull methods, and axes on the left correspond to four tools in market-pull methods. The radius indicates a performance score in Fig 1. The smaller the radius, the lower the score.

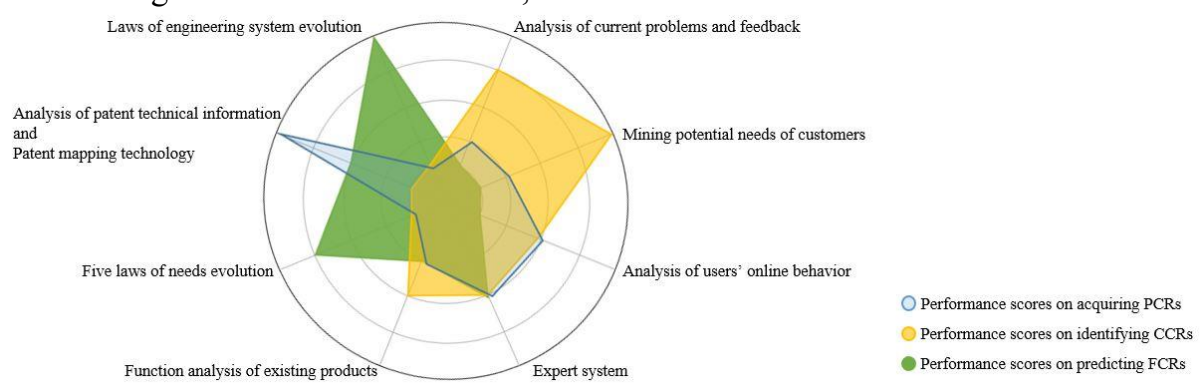

Fig. 1. The performance scores on the radar chart.

There are trade-offs for acquiring CRs both in the market-pull method and technology-driven method. More precisely, analysis of patent technical information and patent mapping technology performs the best in all tools in acquiring PCRs. Mining potential needs of customers does the best in identifying CCRs. Laws of engineering system evolution dose the best in predicting FCRs. Therefore, if a combined approach is formed to exploit the positive characteristics of all the tools, the comprehensiveness and accuracy of research results will be increased to lead successful designs.

\section{Customer Requirements Acquisition Based on Time Iteration}

All CRs as follow-up product design's inputs can be divided into past customer requirements (PCRs), current customer requirements (CCRs) and future customer requirements (FCRs) through a time frame. Depending on different roles they play, we split PCRs into no longer exiting (or unneeded) ones and everlasting (until now) ones. 
We define that CCRs are made up of everlasting ones and new generated ones, and FCRs are the ones predicted by evolution knowledge for future products. Hence, CRs are divided into four parts as shown in Fig. 2: (1)PCRs that have ceased to exist; (2) CCRs that evolved from PCRs until now; (3)CCRs that newly generated; (4)and FCRs predicted by evolutionary knowledge. The collection of CCRs and FCRs, shown on the Fig.2 as (2)(3)(4), constitutes CRs as follow-up product design's inputs. The detail approach for identifying each type of CRs are discussed as follow.

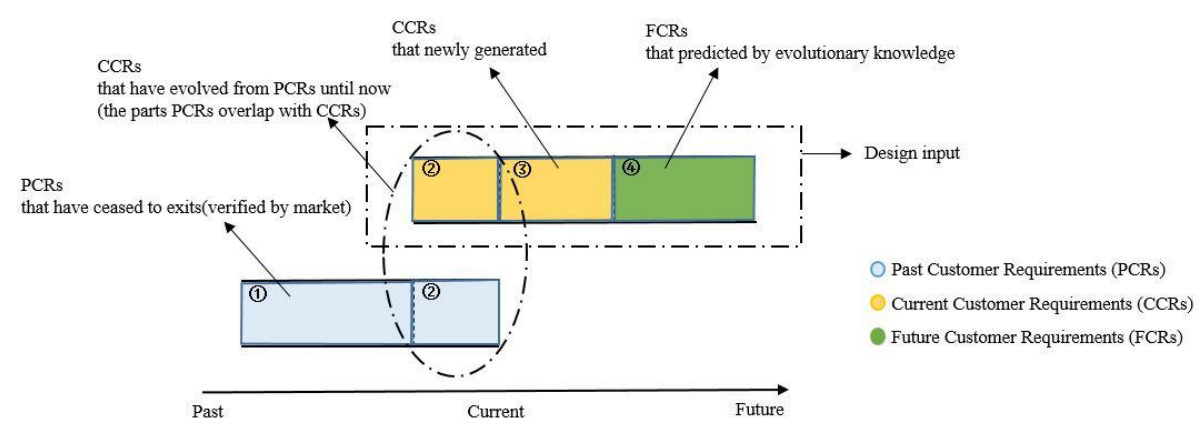

Fig. 2. A Classification of customer requirements in the time dimension.

\subsection{Acquisition of Past Customer Requirements}

As one of the best tools to obtain PCRs, analysis of patent technical information and patent mapping technology can not only acquire PCRs but also extending evolutionary patterns of PCRs.

Leagans defined needs as the gap between the present situation or status quo and a new or changed set of conditions assumed to be more desirable, so the gap between effect of a patent and its technical background at that time can be seen as PCRs. After rough reading patent's 'abstract' and 'summary', sentences describe the effect of it can be extracted, and by comparing 'background of the invention' with the way it achieves its effect, the gap between the status quo and the desirable status can be determined.

Especially, PCRs are described with standard technical expressions, such as '[Direction of improvement], [Object of control], [Parameter]', or '[Direction of improvement], [Parameter]'. On one hand, patent maps, such as an effect matrix, should be constructed under constraints of elements of specific expressions to analyze potential evolution patterns of PCRs. On the other hand, specific expressions will be exploited as inputs of interview's questionnaires or field investigation's preparation files to prevent customers from expressing CRs in casual.

Mastering PCRs can help engineers fully conversant with products and understand origins of CCRs more accurately. PCRs may become more and more important for product design over time, or may no longer exist due to the development of technology and policies. However, the current states of CRs must be determined through communicating with customers. Therefore, the next step will be focusing on customer data. 


\subsection{Identification of Current Customer Requirements}

To identify CCRs means to find no longer existed PCRs, and PCRs that have evolved into CCRs, and whether there are new CRs generated or not. In this paper, customer interviews and field investigations are promoted simultaneously. Before carrying out interviews, it is necessary to define the purpose of the research first.

First, needs of different customers for a same product may vary distinctly. Therefore, differentiating different customers or groups of customers can help better hold opportunities to make decisions made by stakeholders scientifically and commercially [12]. Secondly, customer's behavior in purchasing products is actually 'hire' products to do specific 'jobs' [14]. Therefore, by abstracting higher levels of 'jobs', we can formulate assumptions about CCRs more open to bring more opportunities. Third, CCRs are generated due to constantly appealing for the product design improvement, which is determined by product problems built by customers. All in all, [Type of Customer], [Job], and [Question] constitute CCRs.

The identification of CCRs can be developed as follows. Firstly, product's workflows or functions are extracted from previously acquired PCRs, then they are abstracted as assumptions of [Job] of CCRs. Secondly, an expert team is built for listing all the [Type of customer] (here, pay more attention to the unique attributes of the customers, such as job scenarios, behavioral habits, etc.). [Question] customers may encounter through doing a specific [Job]. Thirdly, [Type of customer], [Job], and [Question] are arranged to build several hypotheses: '[Type of Customer] encountered [Question] when executing [Job]'. Finally, customer interviews and field investigations are conducted to validate and eliminate these hypotheses, as well as to reconstruct other new hypotheses until no new elements are discovered and no hypothesis is denied. By verifying the CCRs expressed in a hypothetical form, the objective can be achieved during identifying CCRs [12].

To make products a top shot in the market, stakeholders often want their products satisfy FCRs. However, FCRs cannot be expressed by customers. On the contrary, it depends on the designer's keen sense of market trends or through the technologydriven power.

\subsection{Prediction of Future Customer Requirements}

Predicting FCRs in the market-pull method is usually based on experts' subjective experience. In 1986, Hippel suggested lead users' present requirements will become general in a marketplace in the future and gave detailed implementation for utilizing lead users in marketing research [15]. However, this method is only clear to those with technical expertise [16]. Since there is no stable basis for neither trend identification nor lead user identification. In fact, to improve the accuracy of predictions, predicting FCRs depends on objective criteria. In addition, the TRIZ-based prediction results based on the objective LESE can provide a high accuracy.

The prediction of FCRs based on LESE can be developed as follows. Firstly, patents are selected and read for solutions to problems of a product, and determine the technological evolution level of the product through analyzing the patterns of the time-varying solutions in the patents. Secondly, the technological evolution law is determined for its application. Thirdly, one or several technological evolution routes 
are selected using this law to predict future states of the product. Finally, the development cycle of the product is identified followed by acquiring the effective future evolutionary states of it, which are FCRs, using several innovative strategies suitable for this stage of the product, such as applicable laws of development of needs.

The pre-verification of the problem identified before improving the accuracy of the predictive process's inputs, and the post-confirmation of innovative strategy can improve the convergence of the predictive process's outputs.

\subsection{Workflow of Customer Requirements Acquisition Based on Time Iteration}

A complete workflow of the proposed approach is shown in Fig. 3, which consists of 7 steps as follows.

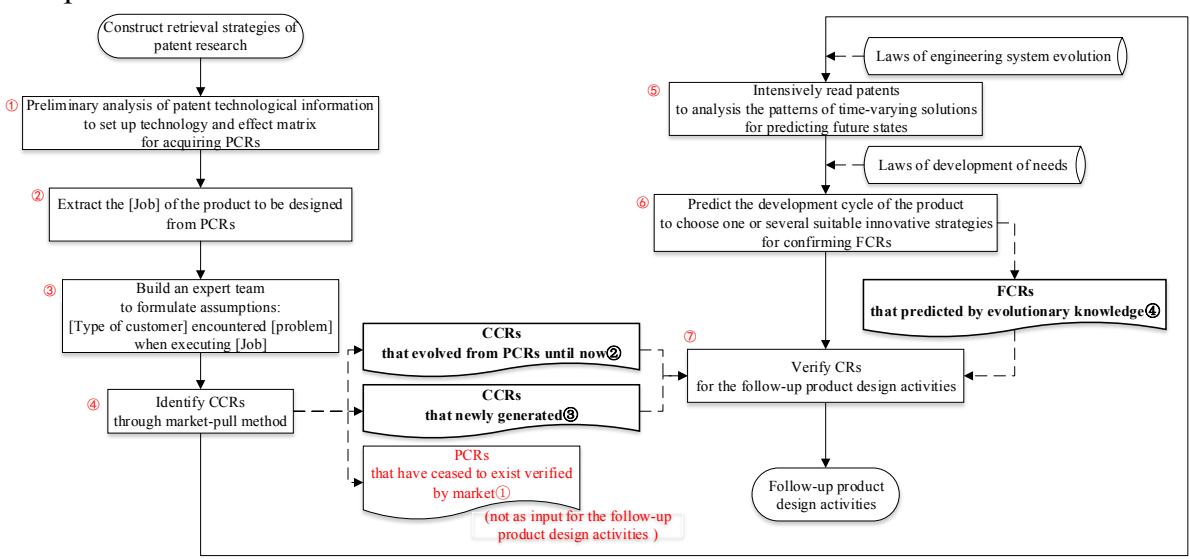

Fig. 3. Workflow of CRs acquisition based on time iteration.

Step 1: Construct retrieval strategies of the patent research by information of products such as business background and working principle followed by a preliminary analysis of the patent technological information to set up the technology and effect matrix for acquiring PCRs.

Step 2: Extract the [Job] of the product to be designed from PCRs.

Step 3: Build an expert team to formulate assumptions: [Type of customer] encountered [problem] when executing [Job].

Step 4: Identify CCRs through customer interviews, field investigations and other tools in market-pull methods. After customer requirements are obtained, so they divided as CCRs that evolved from PCRs until now, CCRs that newly generated, and PCRs that are no longer existed.

Step 5: Intensively read patents to analysis patterns of time-varying solutions for predicting future states of the product.

Step 6: Predict the development cycle of the product to choose one or several suitable innovative strategies for confirming FCRs to be implemented.

Step 7: Verify customer requirement inputs to carry out subsequent design activities. 


\section{$4 \quad$ Case Study}

The spring band hose clamp, stamped from 65Mn spring steel, is a preferred connection standard part for connecting rubber hoses in cooling system vehicle power system, i.e. engine, power battery, etc.). The pincers are used to press the clamp's ears of the outer ring to make the inner ring larger enough to wrap a hose. At present, the most commonly used tools for operating the spring band hose clamps are hand installation pincers, as shown in Fig.4. To liberate the workforce, the handle transmission part of such a hand tool is designed with a force-increasing mechanism, like a spring shown in Fig. 4 (b), or a locking mechanism, like a lock hook shown in Fig. 4(c), as well as lengthen the force arms and shorten the resistance arms (Fig. 4(c)). Moreover, to prevent the clamp from ejecting and accidentally injuring the operator, the jaw is usually designed with a card slot (Fig. 4(b)). Nevertheless, they are still laborious and inefficient in mass production, and it is still impossible to avoid personal injury caused by improper operations or negligence of the operator.

Improved designs of such a product are based on CRs of 'labor-saving' and 'safety' acquired under the guidance of two traditional CRs acquisition methods, it is difficult to trigger radical innovations of such a dedicated tool. The following section reanalyzed the CRs of such a product using the approach proposed in this paper to facilitate the acquisition process.

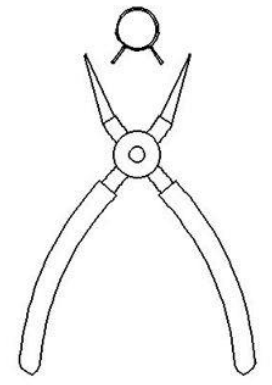

(a)

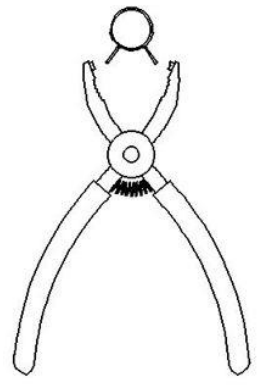

(b)

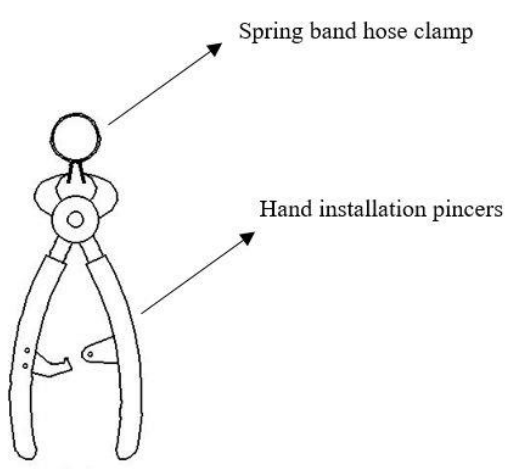

(c)

Fig. 4. Three typical designs of hand installation pincers.

Step 1: Through a Patent Search and Analysis Platform (https://www.zhihuiya.com/), we download all the patents related to design for operating spring band hose clamps. Then we analyze those patents' technical information first and a patent efficacy analysis table is established, as shown in Table 1. 'Effect' extracted from a patent is the PCRs it discloses. All PCRs acquired from patents are listed in Table 2. In this case, we describe [Object of control] as super-system, working unit, energy converter, energy source, control unit, and action objects. When devoted to other products, the perspective and decomposition degree of these parts should be determined according to the specific situation. 
From the information in Table 1, we establish a metric about distribution of patents at different times and different effects (Fig. 5) and another metric about distribution of patents at different times and different system compositions (Fig. 6) for analyzing the trends of PCRs. The larger the diameter of the pie, the greater the number of patents filing for that year. As we can see from Fig. 5, 'Labor-saving' and 'Safety' were the principal PCRs of pincers since 2011. 'Suit for small working space' was fascinated until 2014 and it was gradually ignored and replaced by 'Work-efficiency' and 'Multi-functionality' in 2015. New PCRs like 'Anti-error' and 'Automation' were emerged in 2015. According to Fig.6, the working unit, the energy converter and energy source are governing systems for designer to improve of pincers catering to the PCRs. In 2017, the application of source of the action objects reached a new height, it is nevertheless that the design and improvement ratio of the control unit, the action objects and the super-system is smaller compared with other three items.

Table 1. List of patents and efficacy analysis results.

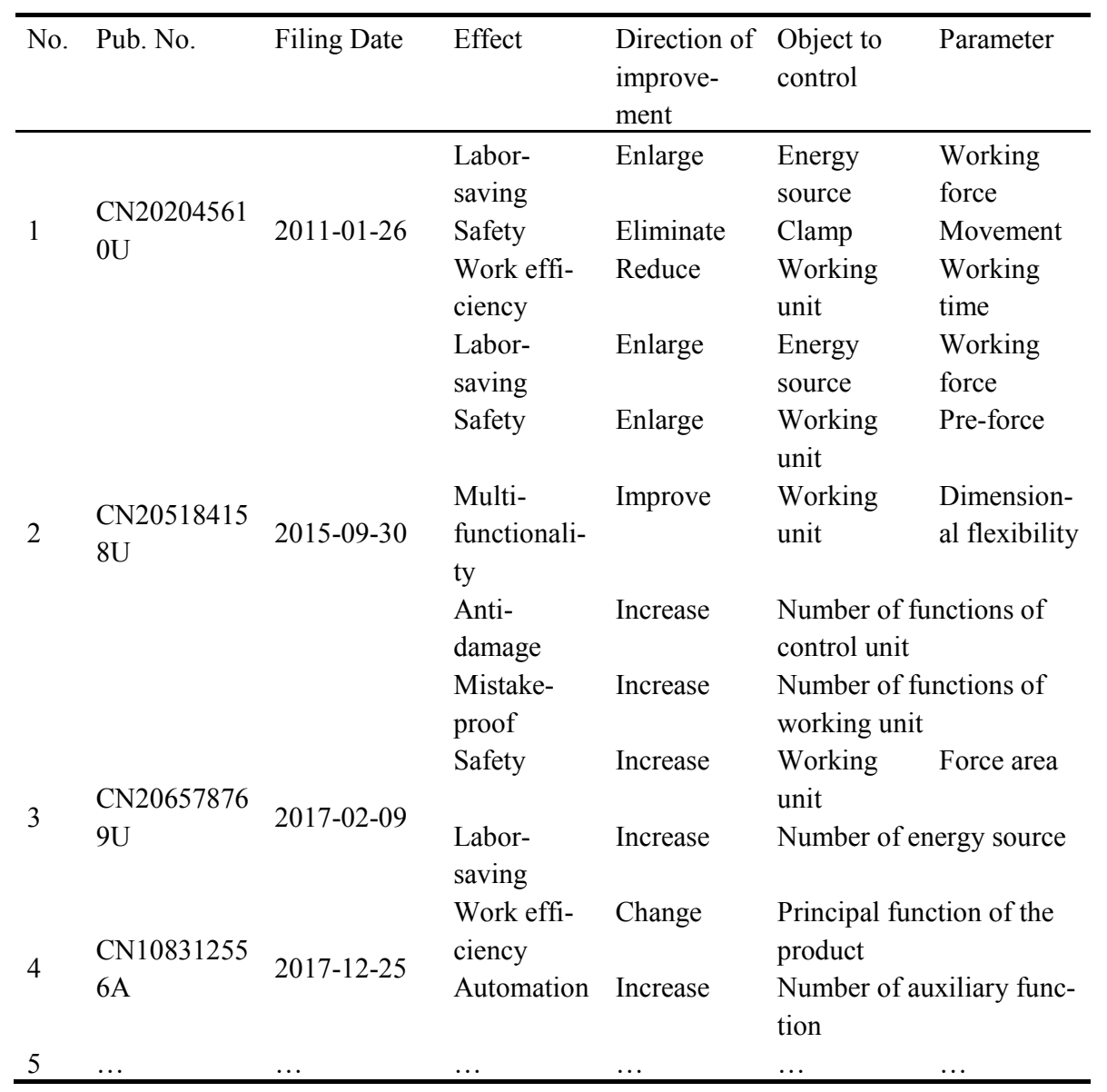


Table 2. PCRs extracting from effects of patents.

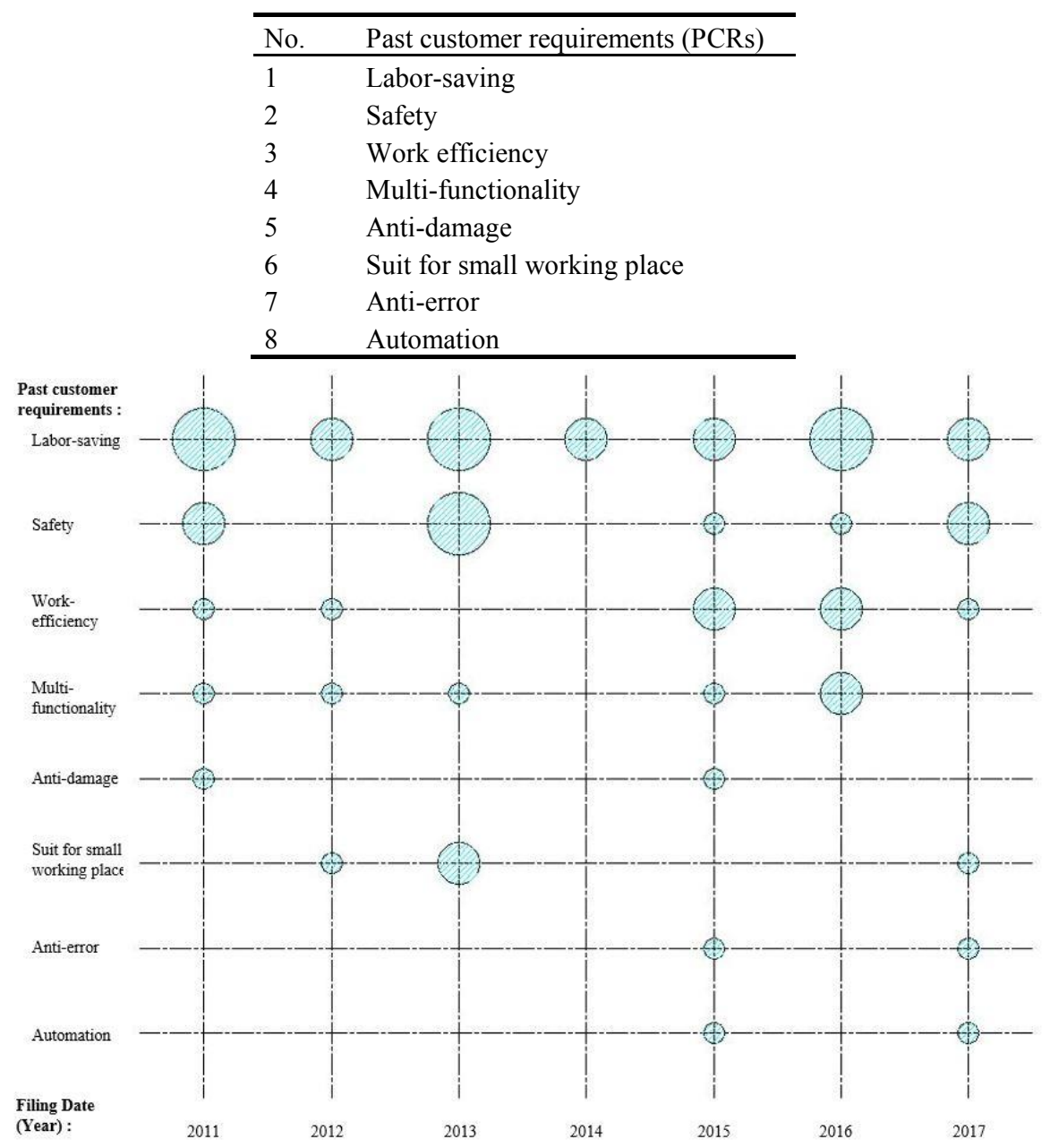

Fig. 5. Distribution of patents at different times and different effects. 


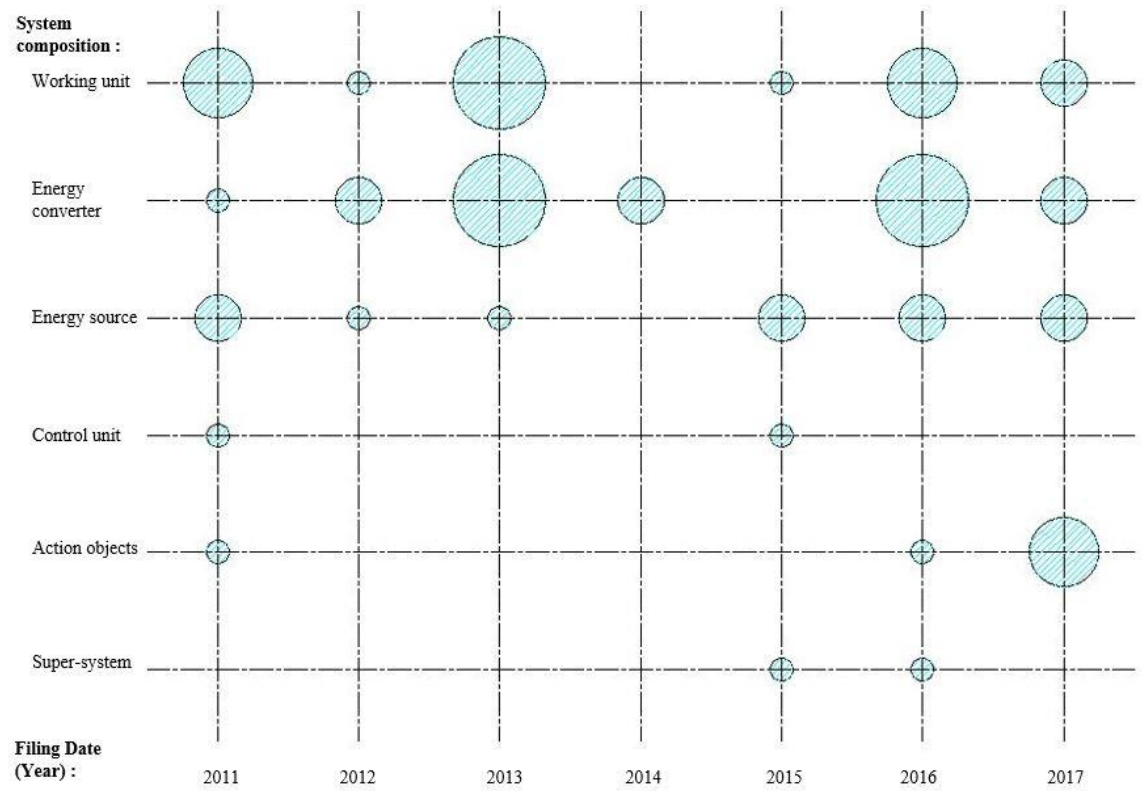

Fig. 6. Distribution of patents at different times and different system compositions.

Step 2: The 'jobs' of designs for operating spring band hose clamps can be extracted from PCRs: "put pressure on ears of clamp in prior", "positioning joint", "positioning hose", "positioning clamp", "operate clamps in high-volume", "clamp multiple types of clamps" and so on.

Step 3: Engineers, craftsmen, sales personnel, etc. are grouped to formulate the assumptions of [Type of customer] and [Problem], respectively. Consequently, assumptions of [Type of customer] include [Workers in pre-assembly line], [Workers in assembly line], [maintenance personnel], etc.; Assumptions of [Problem] include [Clamp repeatedly lead to intensity of labor], [Too much courses lead to low efficiency], etc.

Step 4: Proposal of a questionnaire for customer interviews and field investigations. Eventually, we determine [Type of customer] as 'Workers in pre-assembly line' and verify their problems as 'Clamp repeatedly lead to labor intensity', 'Too much process lead to low efficiency' and 'Poor consistency of clamping position', which are classified into two groups as CCRs that evolved from PCRs until now and CCRs that newly generated. The results are shown in Table 3 . 
Table 3. CCRs of designs for operating spring band hose clamps.

\begin{tabular}{|c|c|c|c|}
\hline Type of customer & Job & Problem & Source \\
\hline \multirow[t]{2}{*}{$\begin{array}{l}\text { Workers in pre- } \\
\text { assembly line }\end{array}$} & $\begin{array}{l}\text { Put pressure on ears } \\
\text { of clamp in prior } \\
\text { Positioning joint } \\
\text { Positioning hose } \\
\text { Positioning clamp }\end{array}$ & $\begin{array}{l}\text { Clamp repeatedly lead } \\
\text { to labor intensity } \\
\text { Too much process lead } \\
\text { to low efficiency }\end{array}$ & $\begin{array}{l}\text { CCRs that } \\
\text { evolved from } \\
\text { PCRs until now }\end{array}$ \\
\hline & $\begin{array}{l}\text { Operate clamps in } \\
\text { high-volume }\end{array}$ & $\begin{array}{l}\text { Poor consistency of } \\
\text { clamping position }\end{array}$ & $\begin{array}{l}\text { CCRs that } \\
\text { newly generat- } \\
\text { ed }\end{array}$ \\
\hline
\end{tabular}

Step 5: Read intensively the patents that focus on solving the problem of 'Clamp repeatedly lead to labor intensity'. Fig. 7 illustrates the change in objects that improved versus time: The cumulative number of patents for implementing working unit improvements before 2013 has been higher than for other unit of the product; In 2015 , the cumulative number of patents for energy converter system improvements has surpassed other units; While at the same time, although the cumulative number of patents for implementing energy source and control unit has increased continuously, they are not significant enough to catch up with. It can be inferred that dealing with this customer requirement, the technical evolutionary route roughly conforms to the 'the law of system completeness'. Specifically, we obtain two future evolutionary states of the product from 'the law of increasing information saturation of a system': 'Introduce a more efficient energy source' and 'Increase energy supply control for energy source'.

Similarly, read intensively the patents that focusing on solving the problem of "Too much process lead to low efficiency", more future states can be obtained. The results are listed in Table 4.

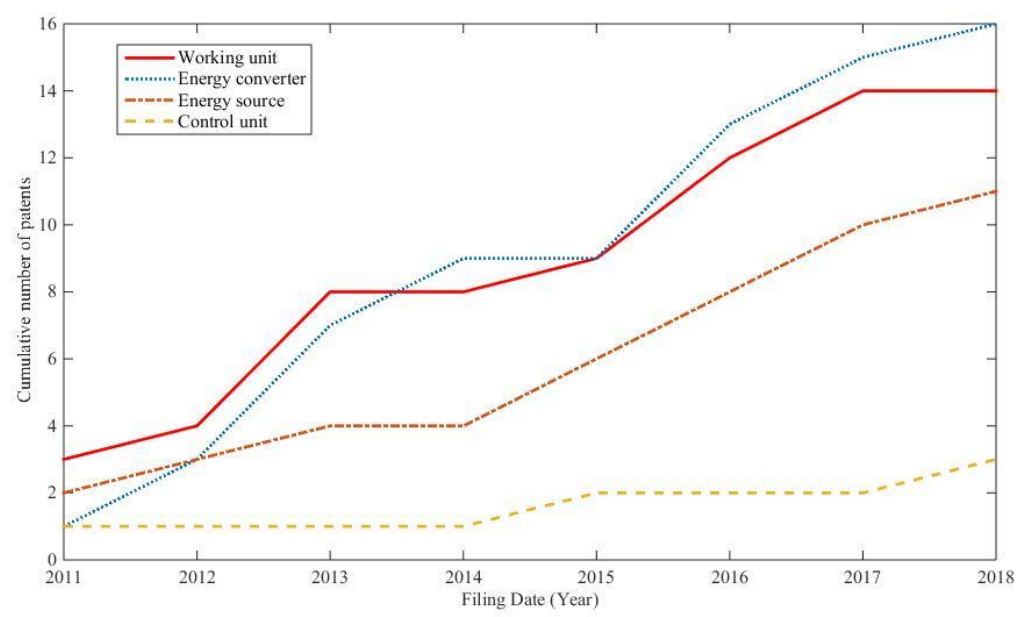

Fig. 7. Change in objects that improved to solve 'Clamp repeatedly lead to labor intensity' versus time. 
Table 4. Future states predicting from evolutionary knowledge.

\begin{tabular}{|c|c|c|c|}
\hline Problem & $\begin{array}{l}\text { law of technical } \\
\text { system }\end{array}$ & $\begin{array}{l}\text { technological evolution- } \\
\text { ary route }\end{array}$ & Future state \\
\hline $\begin{array}{l}\text { Clamp } \\
\text { repeatedly } \\
\text { lead to } \\
\text { labor inten- } \\
\text { sity }\end{array}$ & $\begin{array}{l}\text { The law of system } \\
\text { completeness }\end{array}$ & $\begin{array}{l}\text { Increasing information } \\
\text { saturation of a system }\end{array}$ & $\begin{array}{l}\text { Introduce a more efficient } \\
\text { energy source } \\
\text { Increase energy supply } \\
\text { control for energy source }\end{array}$ \\
\hline \multirow{4}{*}{$\begin{array}{l}\text { Too much } \\
\text { courses } \\
\text { lead to low } \\
\text { efficiency }\end{array}$} & \multirow[t]{3}{*}{$\begin{array}{l}\text { The law of increase } \\
\text { of the degree of } \\
\text { ideality }\end{array}$} & $\begin{array}{l}\text { Increase of a number of } \\
\text { delivered functions }\end{array}$ & $\begin{array}{l}\text { Incorporate the previous or } \\
\text { subsequent courses into the } \\
\text { principal function } \\
\text { Adding more craft pro- } \\
\text { cesses' requirements to the } \\
\text { principal functions, such as } \\
\text { cleaning the pipeline, } \\
\text { sealing the pipe, etc. }\end{array}$ \\
\hline & & $\begin{array}{l}\text { Elimination of undesired } \\
\text { effects }\end{array}$ & $\begin{array}{l}\text { Connect hoses without } \\
\text { clamp }\end{array}$ \\
\hline & & Reduction of cost & $\begin{array}{l}\text { Use expensive materials in } \\
\text { necessary zones only }\end{array}$ \\
\hline & $\begin{array}{l}\text { Irregular evolution } \\
\text { of system parts }\end{array}$ & $\begin{array}{l}\text { Irregular evolution of } \\
\text { system parts }\end{array}$ & $\begin{array}{l}\text { Improve degree of ideali- } \\
\text { zation of the previous or } \\
\text { subsequent courses }\end{array}$ \\
\hline
\end{tabular}

Sep 6: Calculate the technical growth rate (the ratio of invention patent applications or authorizations in a certain technical field to the total number of invention patent applications or authorizations in the technical field in the past 5 years [17]) to predict the development cycle of designs for operating spring band hose clamps. As we can see from Table 5, the technical growth rate was increasing from $11.1 \%$ in 2015 to $27.8 \%$ in 2016 to $28.6 \%$ in 2017 , as well as the interpolation curve of cumulative number of patents granted by years (Fig. 8), which devotes to predict the maturity of a product, we predict that the development cycle of products for operating spring band hose clamps has gradually moved from Infancy to Growth.

In the Growth stage, a large number of new functions, enhancement of performance and brand effects should be the main innovative directions [8], reflected in the laws of development of needs is the following three: First, integration. The preoperation and post-process are summed up and intensified. Second, specialization, i.e., specific products should be targeted to specific people. Third, coordination. Coordination could be dynamic, in particular, it can be also understood as intensification of the maximum difference between CRs.

The above-mentioned future evolutionary states were matched with the laws of development of needs, and according to the results in Table 6, 'Connect hoses without clamp' and 'Use expensive materials in necessary zones only' should be deleted. 
Table 5. CCRs of designs for operating spring band hose clamps.

\begin{tabular}{llllllll}
\hline Filing Date (Year) & 2011 & 2012 & 2013 & 2014 & 2015 & 2016 & 2017 \\
\hline Filing number of patents & 5 & 3 & 6 & 2 & 2 & 5 & 6 \\
Technical growth rate & $\backslash$ & $\backslash$ & $\backslash$ & $\backslash$ & $11.1 \%$ & $27.8 \%$ & $28.6 \%$ \\
Cumulative number of patents & 5 & 8 & 14 & 16 & 18 & 23 & 29 \\
\hline
\end{tabular}

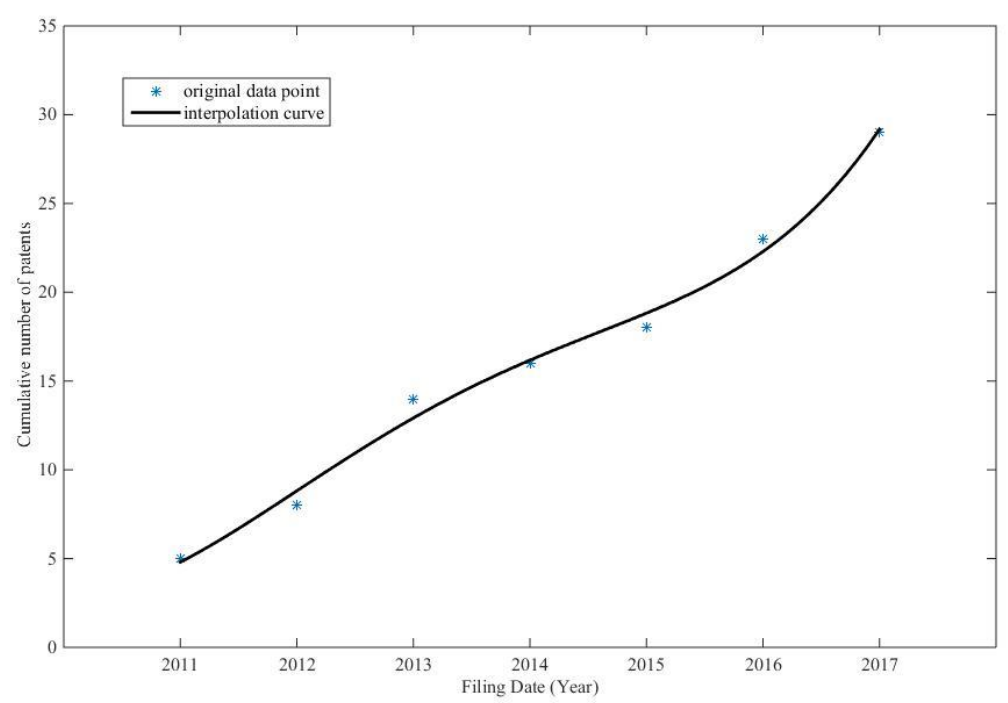

Fig. 8. Cumulative number of patents for operating spring band hose clamps granted through years.

Table 6. CCRs of designs for operating spring band hose clamps.

\begin{tabular}{|c|c|}
\hline Future state & $\begin{array}{l}\text { Corresponding laws of devel- } \\
\text { opment of needs }\end{array}$ \\
\hline Introduce a more efficient energy source. & Coordination \\
\hline Increase energy supply control for energy source. & Dynamization \\
\hline $\begin{array}{l}\text { Incorporate the previous or subsequent courses into the } \\
\text { principal function. }\end{array}$ & Idealization, Integration \\
\hline $\begin{array}{l}\text { Adding more craft processes' requirements to the principal } \\
\text { functions, such as cleaning the pipeline, sealing the pipe, } \\
\text { etc. }\end{array}$ & Idealization, Specialization \\
\hline Connect hoses without clamp. & Idealization \\
\hline Use expensive materials in necessary zones only. & Idealization \\
\hline $\begin{array}{l}\text { Improve degree of idealization of the previous or subse- } \\
\text { quent courses. }\end{array}$ & $\begin{array}{l}\text { Integration, Specialization, } \\
\text { Corodination }\end{array}$ \\
\hline
\end{tabular}


Table 7. Customer requirements (CRs) of schemes for operating spring band hose clamps.

\begin{tabular}{lll}
\hline No. & Customer requirements (CRs) & Source \\
\hline 1 & $\begin{array}{l}\text { Solve the problem of "Clamp repeatedly lead to } \\
\text { labor intensity" }\end{array}$ & $\begin{array}{l}\text { CCRs that evolved from PCRs } \\
\text { until now }\end{array}$ \\
2 & $\begin{array}{l}\text { Solve the problem of "Too much process lead to } \\
\text { low efficiency" }\end{array}$ & $\begin{array}{l}\text { Solve the problem of "Poor consistency of clamp- } \\
\text { ing position" }\end{array}$ \\
4 & $\begin{array}{l}\text { Introduce a more efficient energy source } \\
\text { CCRs that newly generated }\end{array}$ \\
6 & $\begin{array}{l}\text { Increase energy supply control for energy source } \\
\text { into the principal function }\end{array}$ \\
7 & $\begin{array}{l}\text { Add more craft processes' requirements to the } \\
\text { principal functions, such as cleaning the pipeline, }\end{array}$ & $\begin{array}{l}\text { FCRolutionary knowledge } \\
\text { sealing the pipe, etc. }\end{array}$ \\
8 & $\begin{array}{l}\text { Improve degree of idealization of the previ- } \\
\text { ous or subsequent courses }\end{array}$ \\
\hline
\end{tabular}

\section{Conclusions}

The approach proposed in this paper integrated the market-pull CRs acquisition method with technology-driven CRs acquisition method based on time iteration for providing useful indications to support follow-up product design activities. More precisely, we listed a total amount of eight tools that split into the market-pull and technology-driven methods representing different performance of acquiring PCRs, identifying CCRs and predicting FCRs.

As a result, we observed that the market-pull method performs better than the technology-driven method in identifying CCRs, while the latter exceeds the former both in acquiring PCRs and in predicting FCRs. We highlighted that the gap between patents' effect and technical background is PCRs; Patent maps are built based on the PCRs display for the potential evolutionary information of PCRs; Expression elements took the PCRs heritage exploited as inputs of interview's questionnaires, or field investigation's preparation files would prevent customers from expressing CRs in casual to improve the consistency between statements of CRs and representations of engineering designs. Objective laws of the engineering system evolution have good maneuverability for FCRs prediction. Moreover, the statement of the integration of two traditional CRs acquisition methods is a more comprehensive. The accurate way to capturing CRs is observed and confirmed.

With the rapid development of economic environment, companies are no longer satisfied with incremental innovations. They need to generate radical innovations. This proposed approach is especially suitable for conducting radical innovations. Since incremental innovation features improvements in existing requirements, while radical innovation emphasizes new markets, new users, new technology and longterm development platforms. Due to the uncertainty of radical innovation and a pas- 
sive role of users, companies will face severe challenges when they participate in the radical innovation process based on customers. Because users might not be able to or not want to contribute to indiscernible ideas. Thus, we might prefer to use technologybased innovation processes and design-based innovation processes.

It should be noted that the prediction of FCRs in this paper only took into account the chain-type evolutionary routes. In fact, CRs may be developed in a tree-shaped evolutionary patterns. It is necessary to provide a more comprehensive description to apply the proposed approach in the future.

Acknowledgement. This paper was sponsored by the National Science and Technology Basic Project of China (Grant No. 2017IM040100), Support Scheme for 100 Outstanding Innovative talents in Colleges and Universities in Hebei Province (SLRC2017030).

\section{References}

1. Agulyansky, A., Talalaevkski, A., Roggel, A.: TRIZ Usage for Customer Needs Identification Part1, https://triz-journal.com/innovation-methods/innovation-triz-theory-inventiveproblem-solving/triz-usage-customer-needs-identification-part-1/, last accessed 2019/04/16

2. Mann, D.L.: Capturing the voice of the customer before the customer knows what they want: TRIZ, spiral dynamics, and the fourth turning. Procedia Engineering 9, 573-581 (2011). doi:10.1016/j.proeng.2011.03.143

3. Ding, J.W., Yang, D.T., Bao, Z.Q.: Research on capturing of customer requirements based on innovation theory. In: 2012 Conference on Applied Physics and Industrial Engineering, pp. 1868-1880. Elsevier (2012). doi:10.1016/j.phpro.2012.02.275

4. Violante, M.G., Vezzetti, E.: Kano qualitative vs quantitative approaches: An assessment framework for products attributes analysis. Computers in Industry 86, 15-25 (2017). doi:10.1016/j.compind.2016.12.007

5. Sauro, J., Lowis, J.R.: Quantifying the user experience: Practical statistics for user research. 2nd edn. Elsevier, Waltham (2012)

6. Qia, J.Y.: Mining customer requirements from online reviews: A product improvement perspective. Information \& Management 53(8), 951-963 (2016). doi:10.1016/j.im.2016.06.002

7. Chong, Y.T., Chen, C.H.: Management and forecast of dynamic customer needs: An artificial immune and neural system approach. Advanced Engineering Informatics 24, 96-106 (2010). doi:10.1016/j.aei.2009.06.003

8. Cao, G.Z., Tan, R.H.: The principle and application of function design. First edn. Higher education press, Beijing (2016). (in Chinese)

9. Petrov, V.: Laws of development of needs, https://triz-journal.com/laws-developmentneeds/

10. Zhang, J.H., Li, Y., Zhang, P., Zhang, W.M.: Customer needs acquisition by integrating needs evolution with technology evolution. Journal of machine design 34(7), 15-22 (2017). (in Chinese) doi:10.13841/j.cnki.jxsj.2017.07.003

11. Walden, D.: A special issue on: Kano's methods for understanding customer-defined quality. Center for Quality Management Journal 2(4), 1-37 (1993). ISSN: 1072-5296 
12. Lowdermilk, T., Rich, J.: The Customer-Driven Playbook: Converting Customer Feedback into Successful Products. First edn. O'Reilly Media, Sebastopol (2017)

13. Fiorineschi, L., Frillici, F.S., Rotini, F.: Enhancing functional decomposition and morphology with TRIZ: Literature review. Computers in Industry 35, 1-15 (2018) doi:10.1016/j.compind.2017.09.004

14. Christensen, C.M., Raynor, M.E.: Innovator's solution: Creating and sustaining successful growth. First edn. Harvard Business School Press, Boston (2003)

15. Hippel, E.V.: Leader users: a source of novel product concepts. Management Science 32(7), 791-805 (1986). doi:10.1287/mnsc.32.7.791

16. Ross, R., Rouen K., Austin-Breneman J.: Extending lead user theory to participatory codesign: a case study in a base of the pyramid context. In: Proceedings of the ASME 2018 international design engineering technical conferences and computers and information in engineering conference, ASME, vol. 7. AMER SOC MECHANICAL ENGINEERS, New York (2018). doi: 10.1115/detc2018-86009

17. Chen, Y., Huang, Y.Y., Fang, J.G.: Patent information collection and analysis. 2nd edn. Tsinghua University Press, Beijin (2006). (in Chinese) 